Results 7,764 units of drugs for viral diseases were returned during the study period. Of these units, $90 \%$ were recovered by the Pharmacy Department to be dispensed to other patients. However, $10 \%$ cannot be reused due to multidose packaging.

The return of drugs that can be reused is a gain in economic resources of $84.6 \%$ over the total value of returned drugs (€36.371).

Furthermore, the average cost per unit of reused drugs is $€ 4.4$ vs. $7.3 €$ for non-reused. The combos are usually multidose packaged, when it is in these drugs where unitary repackaging would be more efficient.

Conclusions $10 \%$ of the units of drugs for viral diseases returned to the outpatient area must be discarded due to multidose packaging.

Unitary repackaging allows the Pharmacy Department to recover $84.6 \%$ of the cost of returned drugs in this area.

Combos, as well as being more expensive than other drugs, are mostly multidose packaged, preventing reuse.

No conflict of interest.

\section{TCH-035 REPACKAGING OF DRUGS IN UNIT DOSES USING AN AUTOMATIC BLISTER PRECUTTING SYSTEM}

doi:10.1136/ejhpharm-2013-000276.226

S González-Piñeiro, MT Rabuñal-Alvarez, M Calvin-Lamas, B Feal-Cortizas, I PedreiraVázquez, I Martín-Herranz. Complejo Hospitalario Universitario A Coruña, Pharmacy, A Coruña, Spain

Background Storage conditions in the original blister guarantee certain conditions (light protection, humidity). Our hospital pharmacy has a Strokar (manual repackaging machine) and, since 2011, a Blispack (automatic repackaging). Repackaging is carried out by a pharmacy technician for 7 hours/day, from Monday to Friday.

Purpose To describe the activity of the BlisPack.

Materials and Methods Descriptive observational study. Study period: 12 months (May/2011-April/2012). Variables studied: repackaged pharmaceutical specialties, number of unit doses repackaged, number of blister packs processed, number of blister packs rejected, monthly percentage of units repackaged with BlisPack. Data source: BlisPack ADM v1.1 computer application.

Results Number of different drugs repackaged: 118. Number of unit doses repackaged with BlisPack: 333352. Number of processed/ rejected blisters: 18111/2873 (15.86\%). Average monthly BlisPack unit doses repackaged: 27779. Average percentage of BlisPack repackaged: $40.10 \%$. Monthly evolution of numbers of unit doses repackaged in BlisPack and percentage of unit doses repackaged in BlisPack versus total number of unit doses repackaged: May 2011 (22787 and 30.84\%), June 2011 (11350 and 24.88\%), July 2011 (30675 and 38.65\%), August 2011 (24178 and 37.27\%), September 2011 (19502 and 29.84\%), October 2011 (27942 and 47.03\%), November 2011 (31894 and 40.53\%) December 2011 (25722 and 41\%), January 2012 (25628 and 39.26\%), February 2012 (24500 and 46.08\%), March 2012 (41547 and 54.34\%), April 2012 (47627 and $51.58 \%$ ). The 5 drugs with greatest number of unit doses repackaged in BlisPack were: Acfol, Potasion $600 \mathrm{mg}$, Limovan $7.5 \mathrm{mg}$, Lioresal $10 \mathrm{mg}$ and Levothroid $50 \mathrm{mcg}$

Conclusions This new technology allows us to repackage drugs, maintaining the conditions of the original packaging, with a precut automatic blister that simplifies the process of repackaging. There has been a growth in the use of this system compared to traditional repackaging, implying that to managethe new repackaging BlisPack requires a learning curve and the acquisition of handling skills

No conflict of interest.

\section{TCH-036 RESULTS OF A SYSTEMATIC LONG-TERM STABILITY STUDY FOR READY-TO-USE INJECTABLE DRUGS PRODUCED BY A CENTRALIZED INTRAVENOUS ADMIXTURE SERVICE}

doi:10.1136/ejhpharm-2013-000276.227

1.JD Hecq, ${ }^{2} \mathrm{M}$ Godet, ${ }^{3} \mathrm{~J}$ Jamart, ${ }^{2} \mathrm{~L}$ Galanti. ${ }^{1} \mathrm{CHU}$ UCL de Mont-Godinne, Pharmacy, Yvoir, Belgium; ${ }^{2} \mathrm{CHU}$ UCL de Mont-Godinne, Medical laboratory, Yvoir, Belgium; ${ }^{3} \mathrm{CHU}$ UCL de Mont-Godinne, Scientific suppor unit, Yvoir, Belgium

Background Injectable preparations other than parenteral nutrition admixture and injectable cytotoxic drugs could be prepared by Centralised IntraVenous Admixture Service (CIVAS) if the longterm stability of the drugs is known. However, this information is not always available.

Purpose To develop a programme of chemical drug stability analysis in collaboration between the hospital pharmacy, the medical laboratory and a Biostatistics Centre to determine the long-term stability of widely-used injectable anti-infectious and non-antiinfectious drugs.

Materials and Methods After setting up the High Performance Liquid Chromatography (HPLC) method, 25 drugs (10 anti-infectives, 4 anaesthetics, 2 propulsives, 2 detoxifying agents for antineoplastic treatment and 7 drugs with other properties) were reconstituted in a laminar air flow hood. 15 of them were stored directly at $5 \pm 3^{\circ} \mathrm{C}$ and 16 stored in the freezer at $-20^{\circ} \mathrm{C}$, thawed by microwave following a standardised procedure and stored at $5 \pm 3^{\circ} \mathrm{C}$ before use. The stability of the product was evaluated by regression analysis.

Results For each drug, long-term stability varied from 11 days to 70 days. The freeze-thaw treatment by microwave may extend the stability (from 30 to 120 days) and allow batch-scale production of intravenous drugs, less expensive in term of manpower and sterile devices than drug reconstitution on the ward. The results were published by 47 posters in international congresses and by 34 publications in national and international pharmaceutical journals.

Conclusions Our findings contribute to improving the number and variety of drugs that may be take on by a CIVAS. This collaboration led to the foundation in 2009 of a drug stability research group at the University Hospital of Mont-Godinne that has already been awarded 4 prizes and nominations.

No conflict of interest.

\section{TCH-037 RISK ASSESSMENT OF CYTOTOXIC DRUG COMPOUNDING: MANUAL VS. ROBOTIC}

doi:10.1136/ejhpharm-2013-000276.228

'C Bufarini, 'A Marinozzi, 'S Guglielmi, ${ }^{2} \mathrm{M}$ Milani, ${ }^{2} \mathrm{E}$ Omodeo Sale', ${ }^{3} \mathrm{D}$ Paolucci, ${ }^{3}$ V Rosini. ${ }^{1}$ AO Ospedali Riuniti - University Ancona, Pharmacy, Ancona, Italy; ${ }^{2}$ European Institute of Oncology, Pharmacy, Milan, Italy; ${ }^{3}$ Loccioni Group, HumanCare, Moie di Maiolati (AN), Italy

Background Errors in cytotoxic drug compounding can cause serious harm to patients due to the low therapeutic ratio. Robots are intended to decrease the risk of medication errors through $100 \%$ verification and traceability of the entire production process.

Purpose This work is aimed at assessing the risk of medication errors in manual and automated compounding, taking into consideration the procedures and controls applied in both cases

Materials and Methods The FMECA technique was applied to the procedures for the manual compounding defined in the Recommendations of the Italian Ministry of Health and to the compounding procedures of the APOTECAchemo robot. The analysis involved two Oncology Pharmacies working with automation in the daily routine since 2007 and 2011 respectively. 5 macro-failure modes for the compounding process were identified and the corresponding Priority Risk Indexes (PRIs) were calculated. 